\title{
A análise de fontes e o modo de vida dos primeiros habitantes do nosso continente: pesquisa arqueológica na Educação Básica ${ }^{1}$
} Source analysis and the way of life of the first inhabitants
of our continent: archaeological research in Basic Education

Pâmela Peregrino da Cruz ${ }^{\star}$

\section{RESUMO}

$\mathrm{O}$ artigo apresenta o plano de uma aula com uso de fontes arqueológicas para estudantes do $6^{\circ}$ ano, bem como o relatório de sua realização. O objetivo é contribuir para que professores de História realizem esta e outras atividades práticas e lúdicas no desenvolvimento de um processo de ensino-aprendizagem prazeroso, consistente e produtivo, possibilitando que os estudantes sejam ativos frente ao objeto a ser conhecido. Atividades como essa podem contribuir para desenvolver a capacidade de análise e construção de conhecimentos históricos dos estudantes, permitindo que eles adquiram habilidades e instrumentos da pesquisa em História e possam utilizá-los para analisar não somente fontes, mas também a própria realidade que os cerca.

Palavras-chave: ensino de História; análise de fontes; Arqueologia.

\section{Abstract}

This article presents a lesson plan with the use of archaeological sources for 6th grade students, as well as the report of its accomplishment. The aim is to assist history teachers in performing this and other practical and ludic activities in the development of an enjoyable, consistent and productive teaching-learning process, allowing students to be active in relation to the object to be known. Such activities can help to develop the ability to analyze and construct students' historical knowledge, enabling them to acquire skills and tools of research in History and use them not only to analyze sources, but also the very reality surrounding them.

Keywords: History teaching; source analysis; Archaeology.

Neste artigo apresentarei o plano de uma aula com uso de fontes arqueológicas para estudantes do $6^{\circ}$ Ano, bem como o relatório de sua realização.

\footnotetext{
* Mestre em História Social pela UFF e em Educação pela PUC-Rio. Secretaria Estadual de Educação, Rio de Janeiro. pampcruz@gmail.com
} 
Meu objetivo é contribuir para que professores de História possam realizar esta e outras atividades práticas e lúdicas no desenvolvimento de um processo de ensino-aprendizagem prazeroso, consistente e produtivo. Note-se que não falo apenas de uma aprendizagem prazerosa, mas sim de um processo no qual todos os sujeitos possam se envolver sem dicotomizar o conhecimento do prazer em acessá-lo e produzi-lo.

Em julho de 2009 iniciei minhas atividades profissionais na Rede Estadual de Educação do Rio de Janeiro, lecionando História para turmas do ensino fundamental. Busquei basear minha prática nos fundamentos educacionais e políticos com os quais me comprometi ainda na graduação, quando minha prática docente teve início. Sendo assim, busquei desenvolver um ensino de História que tivesse o diálogo como referência central e a emancipação humana como objetivo final, contribuindo para a formação de pessoas comprometidas com a participação e transformação coletiva da realidade. Para tanto, iniciei o desenvolvimento de diversas atividades práticas que articulavam necessidades e interesses dos estudantes ao conhecimento historicamente acumulado, possibilitando a construção de novos conhecimentos ao criarmos um processo ativo frente ao objeto a ser conhecido. Nesse processo os estudantes deparam com objetos de estudo que precisam de procedimentos presentes também na pesquisa acadêmica para serem compreendidos. Essa prática vai ao encontro do que afirma Sonia Wanderley sobre o campo de pesquisa em História e o seu ensino:

A preocupação de educadores e profissionais antecipa uma metodologia de ensino-aprendizagem em História consolidada na necessidade do desenvolvimento de instrumentos que possibilitem o incremento da autonomia intelectual dos alunos a partir de um refinamento do pensamento. Este refinamento relaciona-se à preocupação com o desenvolvimento de habilidades cognitivas facilitadas pelas especificidades da produção do conhecimento histórico. Classificar, descobrir critérios contidos em classificações, comparar, relacionar, levantar hipóteses etc. são algumas das atividades mentais que podem caminhar juntas com o ensino de História. $^{2}$

Nas primeiras aulas do ano busco compreender o que os estudantes desejam, o que os limita e o que os estimula. Desenvolvo então um planejamento em diálogo com os estudantes que também leva em consideração a experiência 
e os conhecimentos acumulados na minha prática nos anos anteriores. Nesses diagnósticos, desde o início ficou claro (e cada vez mais se reafirma) a necessidade de desenvolver aulas utilizando recursos variados que possibilitem a participação intensa dos estudantes. Essa interação encontra respaldo na produção da pesquisadora Maria Auxiliadora Schmidt. Segundo ela, é a relação do aluno com o procedimento de pesquisa do conhecimento da História que possibilita a produção de conhecimento em sala de aula. Assim:

O professor de História pode ensinar o aluno a adquirir as ferramentas de trabalho necessárias; o saber-fazer, o saber-fazer-bem, lançar os germes do histórico ... Ensinar História passa a ser, então, dar condições para que o aluno possa participar do processo de fazer, de construir a História ... A aula de História é o momento em que, ciente do conhecimento que possui, o professor pode oferecer a seu aluno a apropriação do conhecimento histórico existente, através de um esforço e de uma atividade com a qual ele retome a atividade que edificou esse conhecimento. $^{3}$

Busquei, portanto, estimular o desenvolvimento de diversas formas de expressão, assim como utilizei diversas linguagens para trabalhar com conhecimento dos processos históricos selecionados para o currículo. Sabemos, entretanto, que poucos cursos de formação de professores de História possibilitam/aprofundam a construção de ferramentas de ensino diversificadas e isso, muitas vezes, impõe limites ao processo de ensino-aprendizagem. Neste artigo, apenas uma atividade será apresentada, o que certamente é muito pouco. No entanto, essa atividade apresenta alguns aspectos importantes a serem considerados no planejamento e construção das aulas. A aula que será apresentada começou a ser construída no início da minha carreira profissional, em 2009, na Rede Estadual de Educação do Rio de Janeiro. Ao longo do tempo foi revista e reformulada com base nos resultados, bem como nas colocações e demandas trazidas pelos estudantes. Além disso, as condições de realização também variaram e nem sempre foi possível a realização com todos os recursos, mas ainda assim atingia seus objetivos. Em 2012, a atividade foi contemplada com o $1^{\circ}$ lugar do Prêmio de Ensino Anpuh-Rio José Luiz Werneck da Silva.

A atividade relatada ocorreu no Instituto de Aplicação Fernando Rodrigues da Silveira (CAp-Uerj), com três turmas do $6^{\circ}$ Ano do Ensino Fundamental. Para a série citada o programa de História do CAp-Uerj prevê, 
para o primeiro período letivo, a abordagem de dois pontos: o primeiro instrumental (sobre a pesquisa histórica, fontes, organização do tempo, o ser humano como objeto e sujeito da História) e o segundo sobre as primeiras comunidades humanas. A aula "Pesquisa Arqueológica: analisando fontes e conhecendo modos de vida dos primeiros habitantes do nosso continente", que será apresentada neste artigo, foi desenvolvida como uma ponte entre esses dois pontos. O objetivo era analisar fontes visuais e fósseis para a construção do conhecimento histórico sobre comunidades sem registros escritos. Privilegiou-se o contato com fontes ligadas ao modo de vida de povos do nosso continente (pré-colombianos), como forma de iniciar o tópico seguinte do planejamento anual que trata justamente desses povos. Nessa aula, os estudantes puderam vivenciar um dia como arqueólogos. Munidos de luvas, pás, pincéis e pranchetas eles foram até o pátio da escola e escavaram em busca de artefatos dos primeiros humanos que habitaram nosso continente (minirréplicas de ossos, crânios, casas, fogueiras, roupas de peles, ferramentas etc.). Depois de encontrar seus artefatos, os estudantes os analisaram em busca de descobrir onde e como viviam aqueles seres humanos, como era o clima, do que se alimentavam, quais eram seus hábitos etc. A aula desenvolveu-se ao longo de três tempos de 50 minutos ( 1 hora e 40 minutos no primeiro dia de atividade e mais 50 minutos no segundo dia), nas turmas 61, 62 e 63 do Instituto, em abril de 2012.

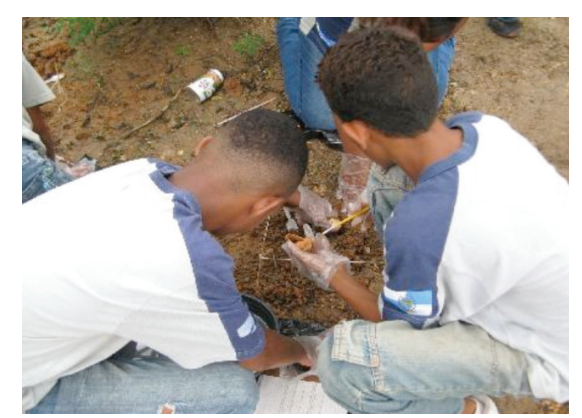

Figura 1 - Pesquisa Arqueológica em Escola Estadual, RJ, 2010.

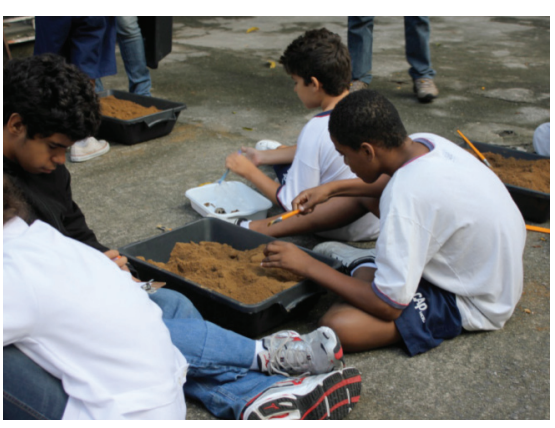

Figura 2 - Pesquisa Arqueológica no CAp-Uerj, 2012. 
A realização da aula contou com estas etapas:

\begin{tabular}{|c|c|c|c|}
\hline Etapa & Atividade & Materiais utilizados & Envolvidos \\
\hline Pesquisa & $\begin{array}{l}\text { Pesquisa sobre os modos de } \\
\text { vida dos povos pré- } \\
\text { colombianos e os vestígios } \\
\text { por eles deixados. }\end{array}$ & Livros e sites. & Professora \\
\hline Pré-produção & $\begin{array}{l}\text { Modelagem e construção de } \\
\text { fósseis em miniaturas. }\end{array}$ & $\begin{array}{l}\text { Gesso, biscuit, silicone, } \\
\text { madeira, pedra, } \\
\text { pelúcia, argila sintética, } \\
\text { verniz e betume. }\end{array}$ & Professora \\
\hline $\begin{array}{l}\text { Organização } \\
\text { do espaço }\end{array}$ & $\begin{array}{l}\text { Compra de terra e caixas de } \\
\text { plástico (caixa de fazer massa } \\
\text { para obra); escolha de um } \\
\text { espaço da escola com pouco } \\
\text { trânsito de pessoas para } \\
\text { colocar as caixas com terra } \\
\text { nas quais foram enterrados } \\
\text { os fósseis }\end{array}$ & Terra e caixas. & $\begin{array}{l}\text { Professora, } \\
\text { Direção e } \\
\text { funcionário do } \\
\text { CAP-Uerj }\end{array}$ \\
\hline $\begin{array}{l}\text { Organização } \\
\text { dos materiais } \\
\text { de trabalho }\end{array}$ & $\begin{array}{l}\text { Compra e organização de } \\
\text { pincéis, espátulas de madeira } \\
\text { e plástico, luvas descartáveis, } \\
\text { bandejas de plástico para os } \\
\text { fósseis encontrados. } \\
\text { - Aviso para os estudantes } \\
\text { levarem luvas e jalecos } \\
\text { utilizados na aula de Ciências } \\
\text { (buscando evitar o contato } \\
\text { com o solo). } \\
\text { - Preparação do kit de } \\
\text { emergência para consertar os } \\
\text { fósseis que pudessem vir a ser } \\
\text { danificados (supercola e } \\
\text { adesivo epóxi). }\end{array}$ & $\begin{array}{l}\text { Pincéis, espátulas de } \\
\text { madeira e plástico, } \\
\text { luvas descartáveis, } \\
\text { bandejas de plástico. } \\
\text { Supercola e adesivo } \\
\text { epóxi. } \\
\text { Luvas e jalecos. }\end{array}$ & Estudantes \\
\hline
\end{tabular}




\begin{tabular}{|c|c|c|c|}
\hline $\begin{array}{l}\text { Breve aula } \\
\text { expositiva } \\
\text { sobre a } \\
\text { pesquisa } \\
\text { arqueológica }\end{array}$ & $\begin{array}{l}\text { Retomada de explicações de } \\
\text { aulas anteriores sobre a } \\
\text { permanência de objetos e } \\
\text { fósseis ao longo dos anos, } \\
\text { sobre o processo de } \\
\text { escavação e análise de fontes } \\
\text { visuais e fósseis. }\end{array}$ & Giz e quadro negro. & $\begin{array}{l}\text { Professora e } \\
\text { estudantes do } \\
6^{\circ} \text { ano do } \\
\text { ensino } \\
\text { fundamental } \\
\text { do CAP-Uerj }\end{array}$ \\
\hline $\begin{array}{l}\text { Pesquisa } \\
\text { arqueológica }\end{array}$ & $\begin{array}{l}\text { Deslocamento dos estudantes } \\
\text { até o 'sítio arqueológico' da } \\
\text { escola, escavação e limpeza } \\
\text { dos fósseis } \\
\text { em grupos. }\end{array}$ & $\begin{array}{l}\text { - Luvas, jalecos, } \\
\text { pincéis, espátulas, } \\
\text { bandejas, pranchetas } \\
\text { com fichas de pesquisa, } \\
\text { terra, caixas e fósseis }\end{array}$ & $\begin{array}{l}\text { Professora, } \\
\text { estagiários da } \\
\text { licenciatura } \\
\text { em História da } \\
\text { Uerj e } \\
\text { estudantes do } \\
6^{\circ} \text { ano do } \\
\text { CAP. }\end{array}$ \\
\hline $\begin{array}{l}\text { Análise dos } \\
\text { fósseis }\end{array}$ & $\begin{array}{l}\text { Deslocamento para a sala de } \\
\text { aula com os fósseis } \\
\text { encontrados e finalização do } \\
\text { preenchimento das fichas de } \\
\text { pesquisa em grupo. }\end{array}$ & $\begin{array}{l}\text { - Fósseis e fichas de } \\
\text { pesquisa }\end{array}$ & $\begin{array}{l}\text { Professora e } \\
\text { estudantes do } \\
6^{\circ} \text { ano }\end{array}$ \\
\hline Apresentação & $\begin{array}{l}\text { Apresentação oral dos } \\
\text { grupos, expondo o que } \\
\text { descobriram sobre as fontes } \\
\text { encontradas. }\end{array}$ & $\begin{array}{l}\text { - Fósseis e fichas } \\
\text { preenchidas }\end{array}$ & $\begin{array}{l}\text { Professora e } \\
\text { estudantes do } \\
6^{\circ} \text { ano }\end{array}$ \\
\hline $\begin{array}{l}\text { Debate e } \\
\text { exposição oral }\end{array}$ & $\begin{array}{l}\text { Debate com toda a turma } \\
\text { sobre as diferenças } \\
\text { encontradas por cada grupo e } \\
\text { explicação sobre os primeiros } \\
\text { modos de vida das } \\
\text { populações do nosso } \\
\text { continente. }\end{array}$ & $\begin{array}{l}\text { - Mapa-múndi e Mapa } \\
\text { da América }\end{array}$ & $\begin{array}{l}\text { Professora e } \\
\text { estudantes do } \\
6^{\circ} \text { ano }\end{array}$ \\
\hline
\end{tabular}

Após todo o processo de pré-produção com a modelagem e construção dos fósseis eles foram enterrados em caixas de plástico para que os estudantes pudessem escavar. As caixas foram necessárias porque o CAP-Uerj não possui um espaço com terra, sua superfície é completamente cimentada.

No primeiro dia de aula, encontrei os estudantes na sala de aula e fiz uma breve explicação sobre a pesquisa arqueológica, retomando pontos que já havíamos 
trabalhado em aulas anteriores. Durante a aula expositiva os estudantes foram estimulados a apresentarem suas questões. Algumas estudantes colocaram dúvidas sobre, por exemplo, os fósseis estarem embaixo da terra. Após cerca de 25 minutos, solicitei que os estudantes se organizassem em grupos de até quatro estudantes e vestissem seus jalecos e luvas para irmos até o ‘sítio arqueológico’ da escola. Como as turmas do Instituto possuem entre 30 e 32 estudantes, foram formados 8 grupos. Avisei que os fósseis a serem encontrados eram réplicas em miniatura feitas por mim, mas mereciam o mesmo cuidado que o arqueólogo precisa ter com os fósseis reais. (Claro que, ainda assim, alguns acidentes aconteceram...) Em seguida, entreguei as ferramentas de pesquisa para cada grupo. Cada kit era composto por:

- 1 bandeja de plástico;

- 1 prancheta com ficha de pesquisa;

- 3 espátulas de madeira;

- 3 pincéis;

- 3 espátulas de plástico.

Munidos com suas ferramentas e vestidos com seus jalecos e luvas, os alunos foram para a parte de trás da escola (chamada popularmente de "Mangueira" em razão da árvore que lá se encontra), onde estavam as caixas previamente preparadas. Avisei que cada grupo encontraria 5 fósseis diferentes, e que a ficha deveria ser preenchida à medida que eles fossem encontrados. Começou, então, a animada escavação. Cada fóssil encontrado era uma alegria. Aos poucos os estudantes foram percebendo que os fósseis dos demais grupos eram diferentes. Havia quatro conjuntos de fósseis diferentes (relativos a modos de vida diferentes), por isso cada conjunto de fósseis era encontrado por um par de grupos. Foram estes os conjuntos de fósseis:

\begin{tabular}{|l|l|l|}
\hline & $\begin{array}{l}\text { - Crânio humano (homo } \\
\text { sapiens) }\end{array}$ \\
Modo de vida & - lança \\
ártico & - anzol \\
& - restos de fogueira \\
& - casaco de pele de animal
\end{tabular}


continuação

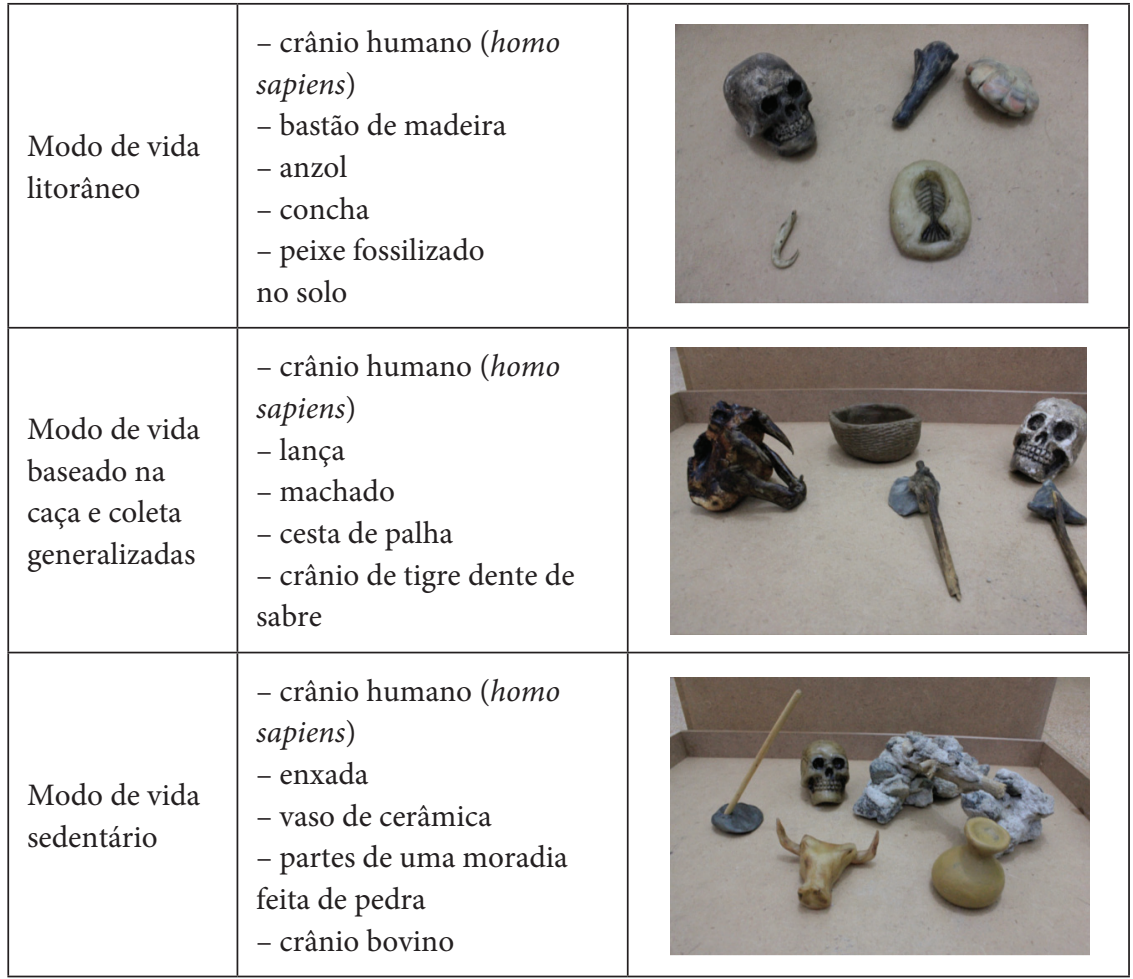

Durante a escavação e coleta dos fósseis os estudantes iam preenchendo sua ficha. Quando todos os grupos encontraram cinco fósseis (depois de aproximadamente 30 minutos), retornamos para a sala de aula com a bandeja. Em sala, os estudantes tiveram cerca de 30 minutos para analisar os fósseis encontrados, motivados pelas questões da ficha de pesquisa. As questões buscavam estimular a problematização das fontes encontradas, tentando reconstituir como aquele humano poderia ter vivido.

Alguns grupos apresentaram dificuldade para começar a interpretação das fontes. Nesses casos eu me aproximava e fazia mais algumas perguntas por exemplo, pegava um dos objetos encontrados e perguntava o que devia ser aquilo, para que era usado, em quais situações ele seria importante, como poderia ter sido feito... Assim, os alunos iam se envolvendo, tentando recompor o passado. Logo descobriam as lacunas, os pontos que não poderiam explicar em razão da falta de fontes. A seguir podemos ver um exemplo de preenchimento da ficha pelos estudantes: 


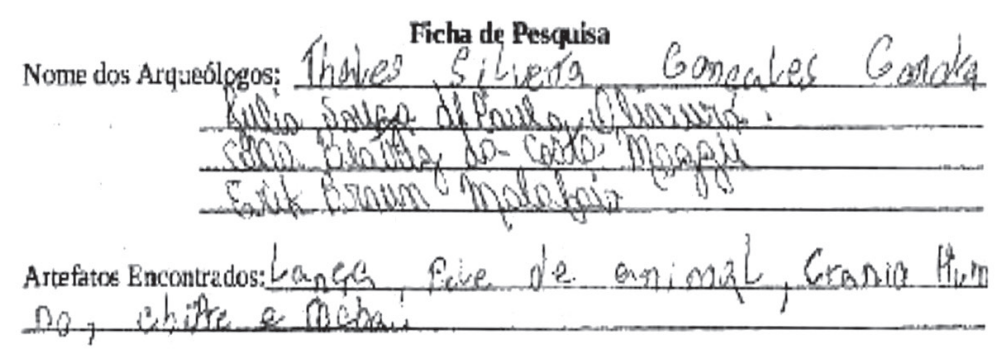

Há algum arefato que posșibillita saber como c̀everia ser o clima e o aspecto da regiăi habitada pelo humano encontrado (Quente, fico, chuvoso, praia, montraba, floresta deserto)? Que gbjeco? Como seria a regiäo?

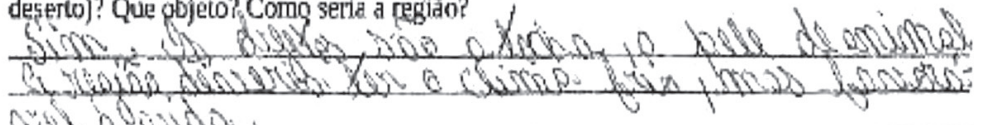

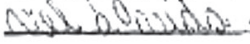

Hó algurn arsefato que indica o que ele devia comer? O que setia? O que ele fazia para conseguir comida?

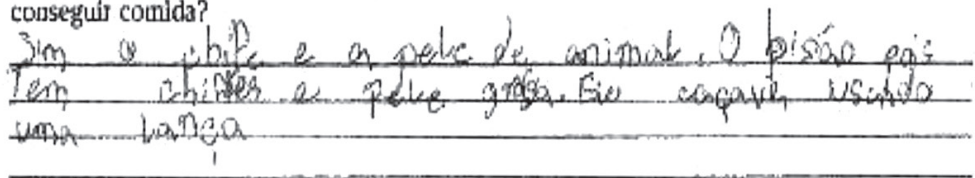

Ele precisava se proteger de algo? Do que ele teria medo? Qual arcefato sugere isso?

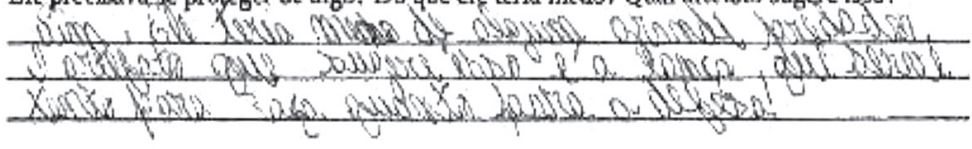

Pelo gue foi enconorado parece que o grupo ceste hamano era nómade (ou seja, precisava se tuidar tocia vez que acabava o alimento) ou sedentário (isto é, vivia em um mesmo luga produaindo seu próprio alimeoto e moradia)? O que leva a esta conclusăo?

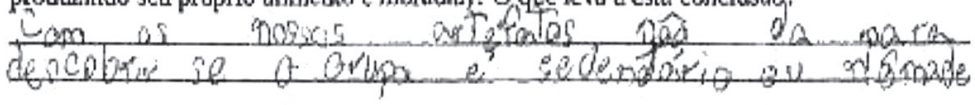

A parti: dos objetos descohertos, *screvem no verso dessa folha um pequeno texto sobre 0 dià-a-dia desse ser humano. 


\section{Hintaresia}

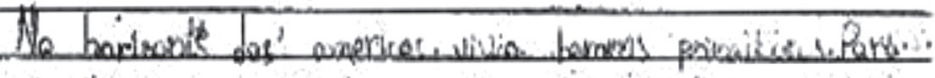

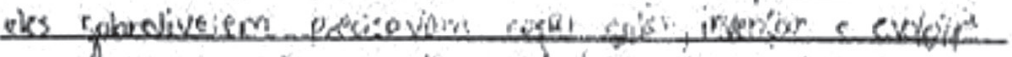

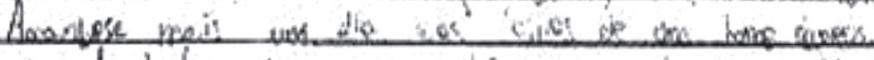

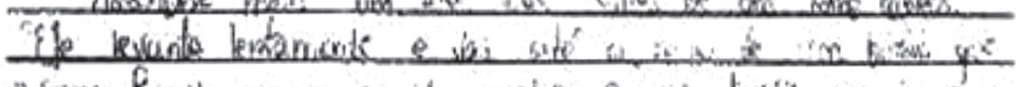

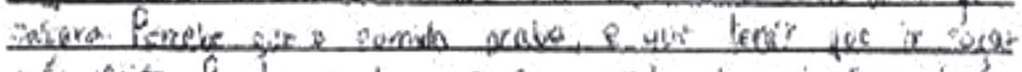

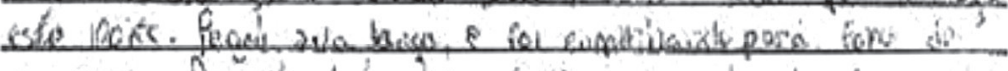

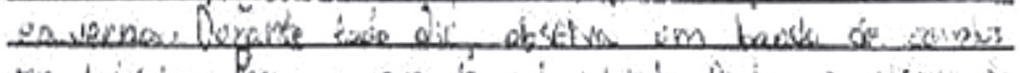

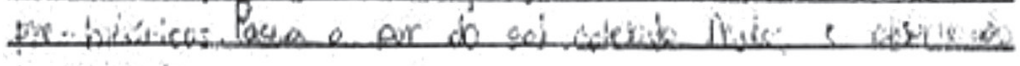
sensumaic.

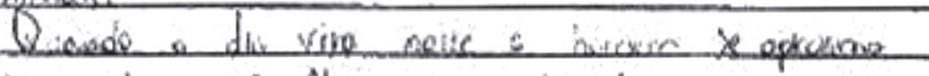

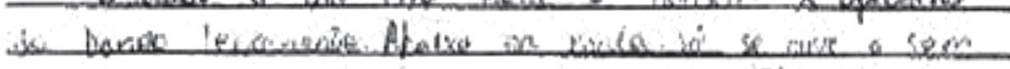

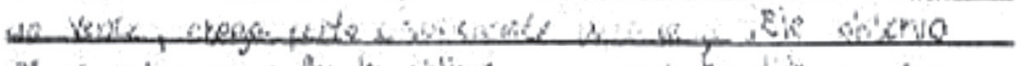

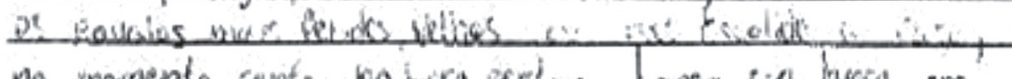

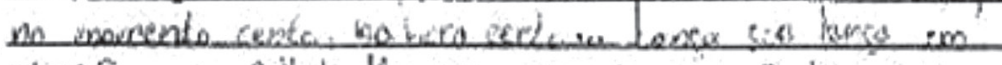

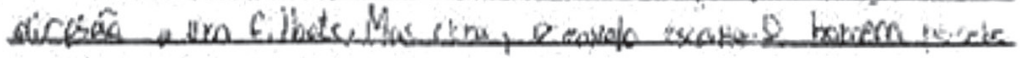

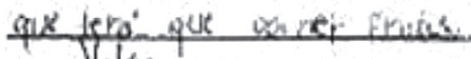

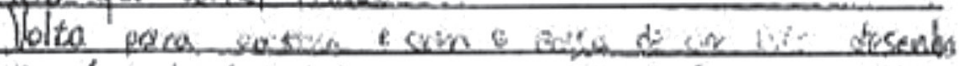

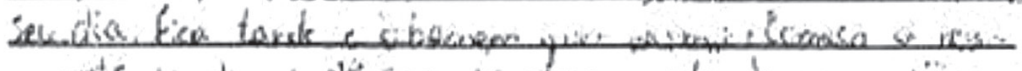

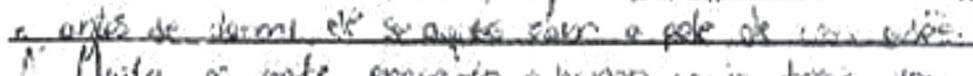

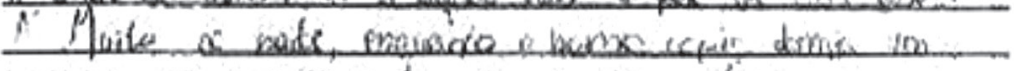

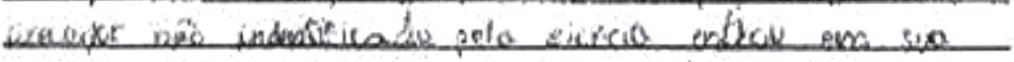

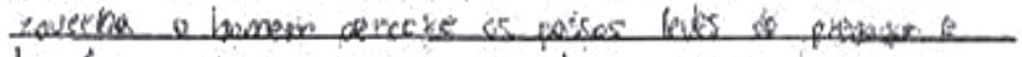

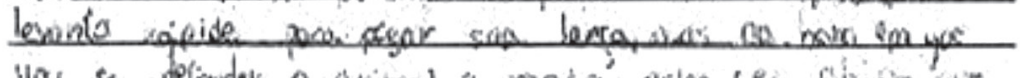

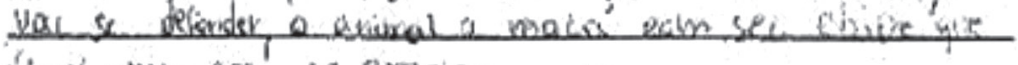

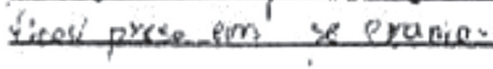

$\frac{i s 5 a \text { of vorias }}{\text { hpolese }}$ 
$\mathrm{Na}$ aula seguinte teríamos 50 minutos para que cada grupo apresentasse seus fósseis e sua análise, bem como para um debate geral e fechamento com uma breve aula expositiva sobre os diversos modos de vida que se desenvolveram em nosso continente muito antes da chegada dos europeus. ${ }^{4}$

À medida que os grupos se apresentavam, alguns pontos interessantes para o estudo da História foram surgindo. Por exemplo, várias versões de interpretação para uma mesma fonte, as lacunas que as fontes deixam, o quanto a falta de vestígios impossibilita certas afirmações. Além dessas questões, surgiam também análises importantes sobre os modos de vida primitivos, como a dependência e a transformação da natureza, o papel da agricultura, o sedentarismo, o intenso trabalho para construção dos conhecimentos e ferramentas necessários para as primeiras comunidades humanas.

Após a última apresentação fizemos um rápido debate sobre a possibilidade de construir conhecimento relacionado a um povo que não deixou registros escritos. Retomamos a questão que eu já havia levantado em outra aula sobre o conceito de "Pré-História" e sobre a ligação dessa ideia à fonte escrita.

Por fim, abri um mapa-múndi e comentei as diferenças climáticas do continente americano e como cada povo que nele se desenvolveu precisou produzir ferramentas e utensílios que possibilitassem a sobrevivência nesses locais. Vimos a importância dos recursos naturais para esses povos e diferenciamos os conceitos de 'economia de depredação' e 'economia de produção'. Comentei, também, que dois povos podem ter modos de vida baseados economicamente nos mesmos aspectos e mesmo assim apresentar compreensões de mundo bastante diferentes, produzindo culturas diferentes em locais com os mesmos recursos naturais.

Minha avaliação dessa aula se baseou em dois aspectos: a reação dos estudantes à atividade e o conhecimento produzido, expresso nas fichas de pesquisa e nas apresentações orais dos grupos.

O primeiro aspecto me leva a realizar uma avaliação extremamente positiva. Realmente, percebo que essa aula vai no caminho que não dicotomiza prazer e aprendizagem. Pelo contrário, os estudantes realizam toda a atividade de forma concentrada, mas demonstrando alegria em descobrir, em conhecer. Além disso, os estudantes assumem uma posição ativa na produção do 
conhecimento e percebem que eu não devo transmitir todo o conhecimento - eles mesmos já possuem ferramentas para interpretar a realidade.

Quanto ao segundo aspecto, avaliei que as fichas e apresentações revelam o quanto os estudantes puderam desenvolver sua capacidade de analisar e construir conhecimento histórico em sala de aula. Em geral, os estudantes conseguiram preencher as fichas de forma interessante, elaborando suas análises e reflexões. Embora algumas fichas tenham apresentado respostas muito simplistas e diretas (e, sem dúvida, estimular uma escrita mais desenvolvida é parte dos desafios da educação), as apresentações foram muito ricas e o debate fluiu com facilidade, pois todos estavam motivados a participar e aprender.

Creio que a aula alcançou todos os objetivos propostos no planejamento (Possibilitar a análise de fontes fósseis para construção do conhecimento histórico sobre comunidades sem registros escritos; Diferenciar modos de vida com economia baseada na depredação e na produção; Relacionar modos de vida e ferramentas aos recursos naturais e ao clima de cada região; Reconhecer os seres humanos como parte da natureza ao mesmo tempo em que a transformam).

Além dos objetivos planejados para essa aula, a pesquisa arqueológica realizada atende aos objetivos mais amplos com os quais me comprometi. $\mathrm{Ou}$ seja, a atividade articula as necessidades e interesses dos estudantes ao conhecimento historicamente acumulado, possibilitando, também, a construção de novos conhecimentos. Permite que os estudantes adquiram habilidades e instrumentos da pesquisa em História e possam utilizá-los para analisar fontes e a própria realidade que os cerca.

\section{NOTAS}

${ }^{1}$ Artigo produzido com base no trabalho "Pesquisa Arqueológica: analisando fontes e conhecendo modos de vida dos primeiros habitantes do nosso continente", vencedor do Prêmio de Ensino Anpuh-Rio José Luiz Werneck da Silva, 2012.

${ }^{2}$ WANDERLEY, Sonia. Repensando o ensino da História, produzindo conhecimento. Caderno de graduação ensino e formação de professores na perspectiva das licenciaturas em Ciências Humanas. Rio de Janeiro: Uerj/Departamento de Ensino de Graduação, v.4, p.3643, 2002.

${ }^{3}$ SCHMIDT, Maria Auxiliadora. A formação do professor de história e o cotidiano da sala 
de aula. In: BITTENCOURT, Circe (Org.). O saber histórico na sala de aula. São Paulo: Contexto, 1998. p.57.

${ }^{4}$ Algumas aulas antes os estudantes haviam confeccionado comigo um globo terrestre no qual puderam marcar os caminhos que os humanos percorreram para chegar à América, desde seu surgimento na África. Ou seja, já possuíam conhecimento sobre as datas de chegada e as teorias explicativas, principalmente o caminho pelo Estreito de Bering e pelo Oceano Pacífico.

Texto recebido em 20 de dezembro de 2012. Aprovado em 14 de abril de 2013. 